\title{
She sees stars
}

\section{This apparatus, held in London's Science Museum, has some significant purpose - or curiosity value - in the history of physics. Can you guess what it is?}
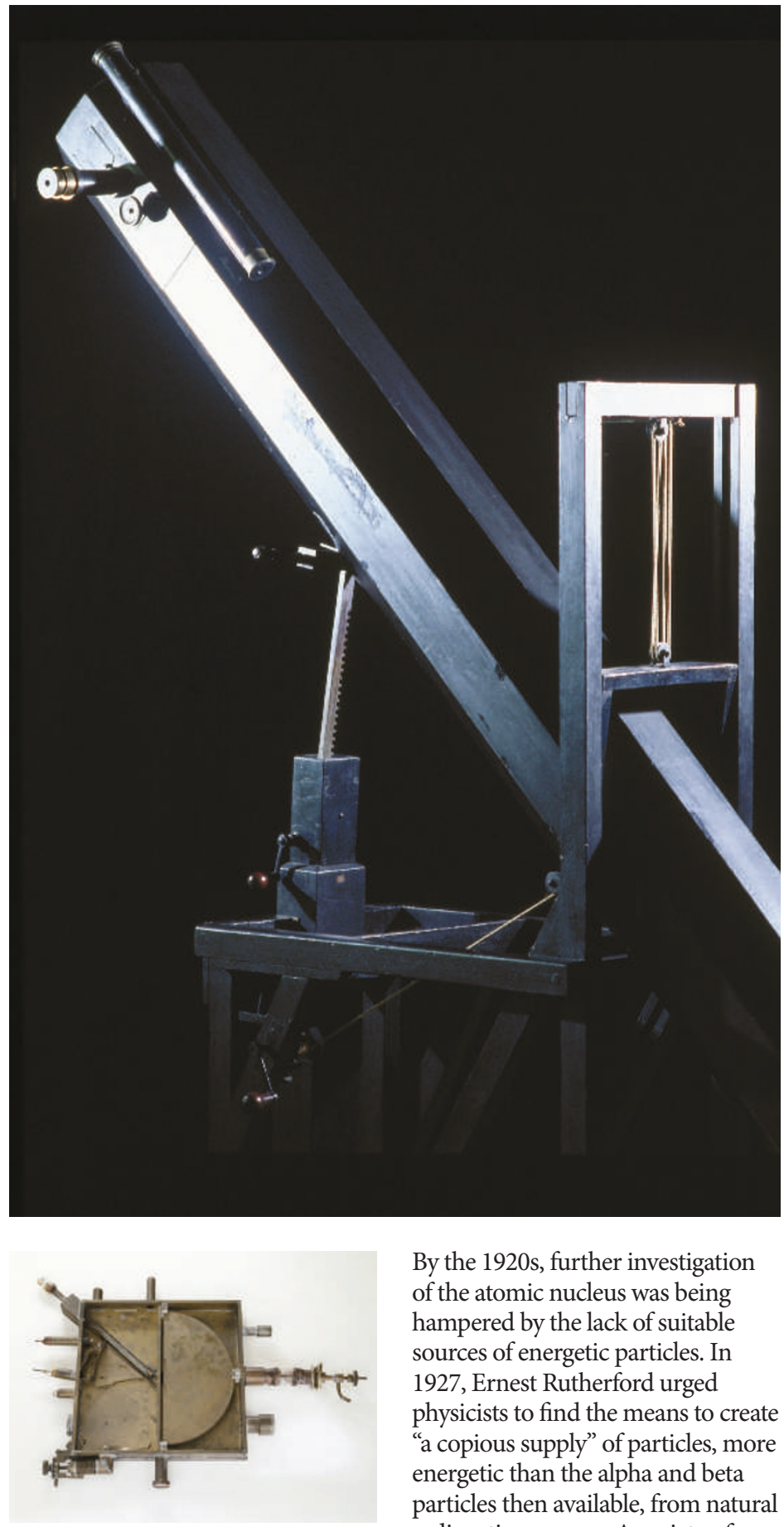

Last month: Lawrence-Livingston cyclotron
By the 1920s, further investigation of the atomic nucleus was being hampered by the lack of suitable sources of energetic particles. In 1927, Ernest Rutherford urged physicists to find the means to create "a copious supply" of particles, more energetic than the alpha and beta particles then available, from natural radioactive sources. A variety of methods were tried: in Cambridge, John Cockcroft and Ernest Walton
WHO WAS

THE COMET-

DISCOVERING

OWNER OF THIS

TELESCOPE?

ANSWER NEXT

MONTH.

\section{science museum}

accelerated protons using a highvoltage transformer and a voltage multiplier; Robert Van de Graaff built an electrostatic high-voltage generator; and Merle Tuve, in Washington, achieved a million volts of accelerating power using a Tesla coil and a Van der Graaf generator.

However, a young rising star at Berkeley called Ernest Lawrence was trying to avoid using very high voltages. Inspired by a paper by Rolf Wideröe, which advocated using the electric potential to accelerate particles twice over, Lawrence devised a way of projecting particles in a circular path and passing them repeatedly through the accelerating potential. This 'cyclotron' would mark a new era of research into particle physics.

His first machine, built with the assistance of graduate student M. Stanley Livingston and completed in January 1931, measured about 4.5 inches across and accelerated hydrogen ions to 80,000 electron volts. Later that year, Lawrence built this example, which measures 11 inches across and can accelerate to energies of $1,200,000$ electron volts.

The device consists of a brass box containing hydrogen at very low pressure. Near the centre, there is a heated filament that emits electrons. These are accelerated by a steady voltage of about 100 volts, and ionize the hydrogen. Then, under the influence of a rapidly alternating voltage, the hydrogen ions (protons) describe a series of semi-circles of increasing radii, through the $\mathrm{D}$-shaped resonator, acquiring more energy at each turn.

\section{JANE WESS}

Jane Wess is a curator at the Science Museum, Exhibition Road, South Kensington, London SW7 2DD, UK. www.sciencemuseum.org.uk 